\title{
God and the Hypothesis of No Prime Worlds
}

\section{Klaas J. Kraay}

Ryerson University

digital.library.ryerson.ca/object/75

Please Cite:

Kraay, K. J. (2006). God and the hypothesis of no prime worlds. International Journal for Philosophy of Religion, 59(1), 49-68.

$\underline{\text { doi:10.1007/s11153-005-2534-9 }}$

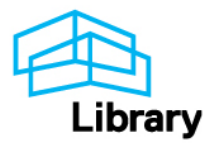




\title{
GOD AND THE HYPOTHESIS OF NO PRIME WORLDS
}

Klaas J. Kraay

Ryerson University

This paper appears in the International Journal for Philosophy of Religion 59 (2006):49-68. The

published version can be found online at: http://www.springerlink.com/content/0020-7047/59/1/.

\begin{abstract}
Many theists hold that for any world $\mathrm{x}$ that God has the power to actualize, there is a better world, $y$, that God had the power to actualize instead of $x$. Recently, however, it has been suggested that this scenario is incompatible with traditional theism: roughly, it is claimed that no being can be essentially unsurpassable on this view, since no matter what God does in actualizing a world, it is possible for God (or some other being) to do better, and hence it is possible for God (or some other being) to be better. In reply to an argument of this sort, Daniel and Frances Howard-Snyder offer the surprising claim that an essentially unsurpassable being could - consistently with his goodness and rationality - select a world for actualization at random. In what follows, I respond to the most recent contributions to this discussion. I criticize William Rowe's new reply to the HowardSnyders (but I endorse the spirit of one of his arguments), and I claim that Edward Wierenga's new defence of the Howard-Snyders fails. I conclude that the HowardSnyders' argument fails to show that an essentially unsurpassable being could randomly choose a world for actualization. Accordingly, it fails to block an important argument for atheism.
\end{abstract}

\section{THE A PRIORI ARGUMENT FOR ATHEISM}

The hypothesis of no prime worlds (NPW) holds that for any possible world $\mathrm{x}$ that an omnipotent being has the power to actualize, there is a better world, $y$, that the being had the power to actualize instead of X. ${ }^{1}$ In recent years, a number of philosophers have urged that NPW is inconsistent with traditional theism. ${ }^{2}$ Such considerations suggest the makings of an a priori argument for atheism on NPW. ${ }^{3}$ In my view, this argument is best expressed as a reductio: 4

(1) On NPW, a being essentially unsurpassable in power, knowledge, goodness, and rationality is possible. [assumption for reductio]

(2) On NPW, it is always possible for the product of the world-actualizing action of This being to have been better. 5

P1 If it is possible for the product of a world-actualizing action performed by some being to have been better, then, ceteris paribus, it is possible for that action to have been better. ${ }^{6}$

(3) Therefore, on NPW, it is always possible for the world-actualizing action of This being to have been better.

P2 If it is possible for the world-actualizing action performed by some being to have been better, then, ceteris paribus, it is possible for that being to have been better.

(4) Therefore, on NPW, it is possible for the being who is essentially unsurpassable in power, knowledge, goodness, and rationality to have been better.

(5) But it is not possible for such a being to have been better.

(6) Therefore, on NPW, no being who is essentially unsurpassable in power, knowledge, goodness, and rationality is possible. 
If this argument is sound, the traditional theist faces a unpalatable choice: either give up (or modify) her traditional theistic belief, or deny NPW.7

\section{THE HOWARD-SNYDERS' OBJ ECTION: J OVE'S RANDOMIZER}

An important objection to this line of argument is advanced by Daniel and Frances HowardSnyder, ${ }^{8}$ who imagine an intriguing thought-experiment: Jove is an essentially unsurpassable being ${ }^{9}$ who desires to actualize a world, but who is unable to actualize a prime world, there being none. Jove divides the set of all (actualizable ${ }^{10}$ ) possible worlds into two subsets based on certain axiologically-relevant criteria. ${ }^{11}$ Worlds in the better subset are given unique integer ordinals: the worst of the lot is ' 1 ', the second-worst ' 2 ', and so on. Jove selects from the better subset at random, and world no. 777 is actualized. ${ }^{12}$ The Howard-Snyders claim that in this story, Jove's "...creating a world inferior to one he or some other possible being could have created does nothing to impugn his status as essentially ... unsurpassable in any respect whatsoever". ${ }^{13}$

On the Howard-Snyders' model, then, world-actualizing-actions involve two steps: the agent (1) selects a partition principle to bisect the set of all actualizable worlds; and (2) decides on a logically-subsequent decision procedure to select a world for actualization from the better subset. If both parts of Jove's world-actualizing action are unsurpassable, even though Jove (or somebody else) could have actualized a better world, then P1 is false. And if it is not the case that both parts of Jove's world-actualizing action are unsurpassable, but Jove is nevertheless himself unsurpassable, then $\mathrm{P}_{2}$ is false. ${ }^{14}$

Before continuing, a terminological issue should be addressed. The Howard-Snyders refer to worlds in the better subset as acceptable worlds, and to worlds in the worse subset as unacceptable, ${ }^{15}$ and Rowe follows them in this. ${ }^{16}$ But this is misleading: if a world's being 'acceptable' entails that it is actualizable by God (and includes God), then the Howard-Snyders have begged the question against the a priori argument for atheism. The very issue at hand, after all, is whether there are any such worlds, and so it will not do to stipulate ab initio that an infinitely-large set of such worlds exists. I take it, then, that the Howard-Snyders (and Rowe) intend some weaker, epistemic sense of 'acceptable': something like 'prima facie acceptable' or 'not obviously such that God would be precluded from actualizing it'. ${ }^{17}$ I will return to this point in Section 4.2., below.

\section{THOR: THE INITIAL DISCUSSION}

To test their claim that Jove is unsurpassable, the Howard-Snyders consider Thor, a rival worldactualizing being. Thor uses the same partition strategy as Jove, but instead of using a random decision procedure, Thor just actualizes world no.888. The Howard-Snyders reject three reasons for thinking that Thor surpasses Jove: 18

(a) Thor does not surpass Jove in virtue of having actualized a better world, since it is a purely random matter that Jove selected world no. 777. Indeed, Jove might well have actualized a better world than Thor's no. 888.

(b) Thor's decision procedure does not surpass Jove's: Thor, in preferring no.888 to no.777, acts on the principle "if there's a better world than w, don't create w", and accordingly (given NPW) it is irrational for Thor to actualize world no.888. ${ }^{19}$

(c) Nor should it be thought that Thor outstrips Jove by acting on a brute preference for world no.888: merely acting on one's preferences does not automatically make a being more rational (or morally better, for that matter) than using a randomizer.

According to the Howard-Snyders, then, the Thor story furnishes no counterexample to the claim that Jove is unsurpassable. William Rowe, however, disagrees: 
Thor doesn't use a randomizing machine but selects world no.888 over Jove's world no.777 because he sees that it is better and prefers creating no.888 to creating any lesser world ... Thor is morally superior to Jove ... for it looks as though Thor's degree of moral goodness is such that he is not prepared to settle for world no. 777 unless he is unable to create a better world. But the fact that Jove intentionally included worlds numbered 1-777 as possibilities for selection by his randomizing machine shows that Jove is morally prepared to settle for any of the worlds from 1777 even though he is able to create a better world ... Thor's degree of moral goodness presumably is such that he is prepared to settle for world no. 888, but not prepared to settle for the world (no.777) that Jove's degree of moral goodness allows him to settle for. We thus have reason to believe that Thor's degree of moral goodness exceeds Jove's, that Thor is morally better than Jove". ${ }^{20}$

In the Howard-Snyders' original telling of the story, Thor uses J ove's partition principle. In this passage from Rowe, however, it sounds as though Thor is understood to have a higher partition principle than Jove has. (But it is not obvious where exactly Rowe thinks Thor's partition point is. All we know is that it is somewhere above world no.777, since Rowe claims that Thor is unprepared to settle for any of worlds 1-777 - worlds which Jove is prepared to actualize.) In their most recent contribution, the Howard-Snyders interpret Rowe to mean that Thor is unprepared to select any world worse than no.888. ${ }^{21}$ The table below displays the various versions of the Thor story in this discussion:

\begin{tabular}{|l|l|l|}
\cline { 2 - 3 } \multicolumn{1}{c|}{} & Thor's Partition Point & Thor's Decision Procedure \\
\hline Howard-Snyders (1994) & just below 1 (just like Jove) & $\begin{array}{l}\text { non-random, } \\
\text { further unspecified }\end{array}$ \\
\hline Rowe (1994) & somewhere above 777 & $\begin{array}{l}\text { non-random, } \\
\text { further unspecified }\end{array}$ \\
\hline Howard-Snyders (1996) & just below 888 & $\begin{array}{l}\text { non-random, } \\
\text { further unspecified }\end{array}$ \\
\hline $\begin{array}{l}\text { Rowe (2002/2004); } \\
\text { Wierenga (2002) }\end{array}$ & just above 800 & randomization \\
\hline
\end{tabular}

The exact position of Jove's partition point is unimportant, however, so long as all the participants in the discussion now agree than Thor's partition point is higher than Jove's. (This, after all, is Rowe's motivation for claiming that Thor should be thought to surpass Jove.) So, if Rowe is right that Thor surpasses Jove in virtue of being unprepared to actualize some worlds that Jove is prepared to actualize, then Jove is not unsurpassable after all. ${ }^{22}$

In reply, the Howard-Snyders point out that Thor either has or lacks a reason for his unpreparedness to actualize a world worse than no.888. If he has such a reason, they plausibly suggest, it must amount to a defensible ${ }^{23}$ partition principle justifying the bisection of worlds just below world no.888. But, the Howard-Snyders claim, (a) it is plausible to suppose (or at least not clearly plausible to deny) that there is a highest such principle, and (b) if so, they are entitled to stipulate that Jove, not Thor, acts on it. ${ }^{24}$ In that case, Thor's partition principle could not possibly surpass Jove's while being philosophically-defensible, and so Thor could not constitute a counterexample to Jove's unsurpassability. ${ }^{25}$ If, on the other hand, Thor lacks a reason for being unprepared to actualize worlds worse than no.888, Thor's decision is either arbitrary or constrained. ${ }^{26}$ Either way, Thor cannot sensibly be thought to surpass Jove.

\section{THOR: THE NEW DISCUSSION}

Since the Howard-Snyders' reply to Rowe was published, several new contributions to this discussion have appeared in print. In what follows, I first consider Rowe's new criticism of the 
Howard-Snyders. I argue that Rowe's criticism fails as stated, but I endorse the spirit of one of his moves. I next claim that Wierenga's new defence of the Howard-Snyders fails. I conclude that the Howard-Snyders' thought-experiment does not block the a priori argument for atheism.

\subsection{ROWE'S NEW CRITICISM OF THE HOWARD-SNYDERS}

The heart of Rowe's new reply to the Howard-Snyders is the following passage:

I believe that the principle on which Thor acts is very much like the principle on which Jove acts. Let's look again at Jove. Some worlds he sees as not good enough to be acceptable as candidates for creation. The worlds that are acceptable to him in terms of his own degree of goodness are then ordered in terms of increasing goodness, and one of them, world 777, is randomly selected for creation. Thor, as I have described him, does pretty much the same thing. The difference is that worlds 1-800 are insufficiently good to be acceptable to him as candidates for creation, given that there are better worlds he can create. The worlds that are acceptable to him in terms of his own degree of goodness are then ordered in terms of increasing goodness and one of them, world 888, is randomly selected for creation. I conclude that the description that the Howard-Snyders give of Jove is logically consistent with there being a being who is better than Jove. And the story we have told about Thor is consistent and, if true, gives us reason to believe that Thor is a better being than Jove. ${ }^{27}$

Note, first, that the Thor story has changed again. In the Howard-Snyders' initial thoughtexperiment, Thor used the same partition principle as Jove, and did not use a randomizer. ${ }^{28}$ Now, however, Rowe explicitly has Thor using a higher partition principle than Jove's, and using a randomizer. (See the table above.)

Given that (on Rowe's new telling of the Thor story) Thor's partition point is clearly held to be higher than Jove's partition point, why does Rowe now claim that Thor and Jove act on the same 'principles'? The answer lies in Rowe's understanding of what these 'principles' are:

Can we state the principles on which both Jove and Thor act, and explain how it is that although they act on the same principles, they produce worlds that differ in their degree of goodness? I suggest that Jove and Thor may act on the following principles:

[PrA]: Do not create any world that is not a good world.

[PrB]: Do not create any good world whose goodness is less than what one judges as acceptable, given that one can create a better world. ${ }^{29}$

Rowe's strategic reason for claiming that Jove and Thor act on the same 'principles' is clear: the Howard-Snyders had stipulated that Jove acts on an unsurpassable principle (or principles) in order to block Rowe from claiming that Thor surpasses Jove. Rowe, thus thwarted, wants Thor to use the same principle(s) as Jove, while nevertheless surpassing Jove.

But, while the Howard-Snyders were concerned with (what I call) partition principles, Rowe now has in mind (what he calls) world-creating principles like PrA and PrB. ${ }^{30}$ The difficulty is that Rowe's world-creating principle PrB suppresses the important difference between Jove's and Thor's partition principles. So, Rowe may be right that both Jove and Thor employ the very general PrA and PrB, but this is irrelevant to the question of whether Thor's world-actualizing action outstrips Jove's: to answer that question, we need to examine both agents' respective partition principles, and their respective logically-subsequent decision procedures. Fortunately, this is now easy to do. As noted, Rowe's recent reply states that Thor has, and uses, a higher 
partition principle than Jove does, but that both use the very same logically-subsequent decision procedure: random selection of a world from the higher subset.

Thor's world-actualizing action, then, should be thought to surpass Jove's action, in virtue of employing a higher partition principle. But, of course, the Howard-Snyders had anticipated this move, and had pre-empted it by claiming that (a) there may only be finitely-many defensible partition principles, and stipulating that (b) if so, Jove acts on the highest of these. In his recent response, Rowe does not directly address (a), but he does imagine the possibility of there being infinitely-many world-creating principles: “... perhaps it is odd that there should be infinitely many world-creating principles. But even if it is odd, we should note that oddness and impossibility are far different matters. Many extremely odd things are logically possible. And if it is logically possible that there is an absolutely infinite number of increasingly better worlds, why should it be impossible that there be an infinite number of principles of world creation?". ${ }^{31}$ This is a tentative suggestion that, possibly, there is no best world-creating principle.

Rowe can offer a much stronger response here. As I noted, (Rowe's) world-creating principles are different from (my) partition principles. A better reply would be to reject the Howard-Snyders' claim that (a) there may only be finitely-many defensible partition principles. Elsewhere, I have argued that the Howard-Snyders' case for (a) is unpersuasive, $3^{2}$ and offered some considerations against (a). ${ }^{33}$ If these are compelling, then (a) should be rejected. But even if there are finitely-many defensible partition principles, and even if Jove acts on the highest and best of these, it does not follow tout court that Jove is unsurpassable. After all - as I have insisted - worldactualizing-actions (in this context) involve two steps: the selection of a partition principle, and the logically-subsequent selection of a decision procedure. It may, then, be the case that while Jove's partition principle cannot be surpassed, Jove's decision procedure can be. For example, a being who uses Jove's randomizer - but then adds one (or any other positive number, for that matter) and selects the resulting world - might plausibly be thought to surpass Jove in virtue of using a better decision procedure (even if such a being is himself surpassable).

To sum up: the Howard-Snyders claim that Jove is unsurpassable, and Rowe aims to challenge this by claiming that Thor surpasses Jove. Rowe's new case rests on the claim that Thor acts on the 'same principles' as Jove does, while nevertheless outstripping Jove. Unfortunately, however, one of the 'principles' that Rowe imputes to both creators - PrB - is ambiguous between different partition principles, and, since these are a key determinant of the goodness of worldactualizing actions, Rowe's PrB is of no use in assessing the relative merits of Jove and Thor. Thor manifestly uses a higher partition principle than Jove does, but the Howard-Snyders tried to stipulate that Jove's partition principle is unsurpassable. This stipulation can plausibly be challenged, but even if it is granted, the Howard-Snyders have still not shown that Jove's decision procedure is unsurpassable. Accordingly, it is reasonable to believe that Jove is surpassable, and (hence) that the Howard-Snyders' thought-experiment fails to block the a priori argument for atheism on NPW.

\subsection{WIERENGA'S NEW DEFENCE OF THE HOWARD-SNYDERS}

I now turn to the most recent attempt to rehabilitate the Howard-Snyders' argument: Edward Wierenga claims that Thor does not surpass Jove, after all.34 Wierenga follows Rowe's new presentation of the Thor story, on which Thor uses a partition principle that divides the set of all actualizable worlds just above world no.80o, while Jove partitions just below world no.1. Each being then randomly selects a world for actualization from the preferred subset. Wierenga's innovation is to deny what others assume: that there is a least acceptable world. 35 Just as it is plausible to suppose that there is no greatest acceptable world, he argues, “... it seems equally plausible that there might be no lowest acceptable level of knowledge and power, no shortest acceptable lifespan, no minimal acceptable amount of pleasure or compensation for evil for a world to be permissible". ${ }^{6}$ From this supposition, Wierenga draws the following conclusion: 
In that case, it is hard to see how Thor in the example could be acting on a nobler [partition] principle or higher standard than Jove. Each picks a world to which infinitely many worlds are superior and which is itself superior to infinitely many other worlds. Thor does not have a principle according to which he rejects as unsuitable more worlds than Jove rejects. There can be no basis for Thor's rejection of worlds lower than [and including] 800, if there are infinitely many in that category; both make an arbitrary choice. These deities can create worlds of differing value without thereby differing themselves in goodness. ${ }^{37}$

First, a comparative point about strategy. Wierenga agrees that Thor's partition principle is higher (in the descriptive sense only) than Jove's is. Like the Howard-Snyders, Wierenga denies that Thor's selection of this partition principle is defensible. But while the Howard-Snyders deny this by claiming that Thor's selection of his partition principle is either arbitrary or constrained because J ove uses (what they implausibly claim to be) the highest partition principle that there is, Wierenga denies this by suggesting that Thor's selection of his partition principle is baseless and hence arbitrary because it is (morally or rationally) equivalent to Jove's selection of his partition principle. ${ }^{3} 8$

Suppose that Wierenga is right to claim that there is no least acceptable world, and that Thor's and Jove's respective selections of partition principles are equivalent, because they are equally baseless and hence arbitrary. This would show (as desired by Wierenga) that Thor does not surpass Jove, but at a significant cost: Jove's selection of his partition principle would then be conceded to be both baseless and arbitrary, in which case one might sensibly wonder whether Jove could be an unsurpassable being at all.39 In contrast, while the Howard-Snyders' claim that Jove acts on the highest partition principle may be implausible, it at least suggests that (a) Jove is doing the best he can in choosing a partition principle; and, a fortiori (given Jove's attributes), that (b) Jove's action in selecting a partition principle cannot possibly be surpassed. These, at least, are credible reasons for thinking that Jove is unsurpassable, but on Wierenga's retelling of the story, these reasons vanish.

Now, suppose only that Wierenga is right to claim that there is no least acceptable world. Does it really follow that Thor's and Jove's respective selections of partition principles are both equally baseless and hence arbitrary? I see no reason to think so. The claim that the set of acceptable worlds has neither an upper nor a lower bound does not entail that all partition principles are baseless and hence arbitrary. World-actualizing agents base their partition principles on a variety of plausible considerations, such as identifying world-good-making-properties that some worlds exhibit and other worlds lack.40 These partition principles, then, may be based and hence non-arbitrary, even if they surpass other partition principles and are themselves surpassable.

Setting these worries aside, though, the heart of the matter is Wierenga's suggestion that there is no least member of the set of acceptable worlds, and that, accordingly, Thor's and Jove's partition principles are equivalent. But what, exactly, might this mean? Here is an initial way of understanding this 'no-minimally-acceptable-world' claim:

NMAW: $\quad$ For any acceptable world $w$ that an unsurpassable deity has the power to actualize, there is a worse acceptable world, $v$, that the deity has the power to actualize instead of $w$.

At first glance, this claim seems objectionably to deny that there is any threshold between acceptable and unacceptable worlds: it seems to entail that any world whatsoever is both acceptable and within God's power to actualize. ${ }^{41}$ But surely this is false: there must be some worlds which are within God's power to actualize, but which are nevertheless outright unacceptable. (Just use your imagination.)

There is, however, a way of understanding this claim to be consistent with the assumption that there is a genuine boundary between acceptable and unacceptable worlds. Suppose that there 
is a precise boundary, but that worlds in the upper subset asymptotically approach it. On this view, then, the infinite set of acceptable worlds asymptotically approaches some lower bound, and NMAW comes out true. We might picture this by thinking of worlds as no longer only corresponding to unique integer ordinals $\{1,2,3, \ldots\}$, but also as corresponding to a set of fractions smaller than 1 , such as $\{1 / 2,1 / 4,1 / 8 \ldots)$. Just as there is no smallest fraction in this range, so too there is no minimally acceptable world on this proposal. $4^{2}$

Rowe, however, seems to deny that NMAW would be true on this interpretation: 43 he holds that if worlds asymptotically approach some lower bound,

... in the downward series of decreasingly good worlds that continually approach but never reach a world with zero degree of good, the difference between one world and the next will eventually be so minimal as to make no detectable, felt difference to any sentient being. Creatures are capable of distinguishing degrees of pleasure and pain, but there are mathematical differences in the amount of pleasure or pain that make absolutely no appreciable, felt difference to the creature. And any difference between one degree of pleasure and a lessor [sic] degree of pleasure that makes absolutely no detectable, appreciable difference to any sentient creature will fail to result in one world being less good or more good than the other. 44

Rowe's central claim in this passage seems to amount to this: if a world, $\mathrm{x}$, contains objectively less good (or more evil) than another world, $\mathrm{y}$, but this difference is not detectable, ceteris paribus, $\mathrm{x}$ is not worse than y. This 'detectability-constraint' strikes me as implausible. I have no knock-down argument against it, but here are some considerations. Rowe appears to assume in this passage that (a) it is a necessary truth that creatures have a threshold beyond which increasingly fine-grained goods and evils simply cannot be experienced, and that (b) undetectable goods and evils cannot affect the axiological status of a world. As for the former, while it may be true that creatures like ourselves cannot detect sufficiently fine-grained distinctions between pleasures or pains, this is no reason to suppose - in a discussion concerning the set of all possible acceptable worlds - that all creatures are similarly-restricted. And as for the latter assumption, it seems a far simpler hypothesis to posit that genuine differences in degree of goodness can have genuine axiological import (even if these differences may be undetectable to creatures like ourselves).

Suppose, then, that - pace Rowe - we grant the coherence of Wierenga's claim that the acceptable worlds asymptotically approach the threshold of acceptability. NMAW, thus construed, is true. But suddenly a question arises: where, exactly, is this boundary? It is tempting to imagine that Wierenga means it to be J ove's partition point: just below world no.1. But this cannot be, since Wierenga claims that, on NMAW, "Thor does not have a principle according to which he rejects as unsuitable more [acceptable45] worlds than Jove rejects". ${ }^{46}$ If the threshold of acceptability were Jove's partition point, then Thor, in partitioning just above world no.80o, would reject infinitely many more acceptable worlds than Jove rejects (and Jove would reject no acceptable worlds). Nor can the threshold of acceptability be Thor's partition point, for then Jove would include unacceptable worlds in the set from which he randomly selects a world - and this set was supposed to contain only acceptable worlds.

For the sake of argument, then, let's suppose that the objective threshold of acceptability is just below some world, w, which is worse than world no.1. And let's continue to suppose that the set of acceptable worlds asymptotically approaches this threshold. Jove partitions at point $\mathrm{j}$, which is higher than w (just below world no.1), and Thor partitions at point t, which is higher still (just above world 800). Given all these assumptions, Wierenga is right to say that "Thor does not have a principle according to which he rejects as unsuitable more [acceptable] worlds than Jove rejects". ${ }^{47}$

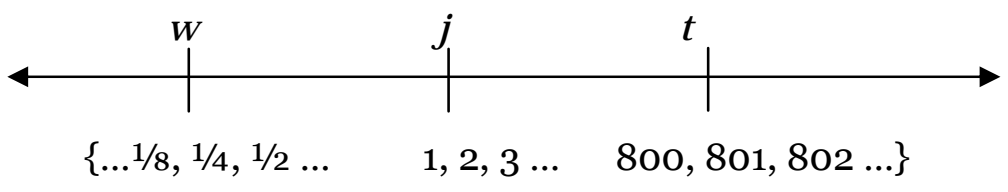


Wierenga's position, then, is that since both partition principles reject an infinite number of acceptable worlds, they are equivalent. Thor may actualize a much better world, but his worldactualizing action is not better than Jove's: (a) his partition principle is deemed equivalent to Jove's for the reason just given; and (b) his decision procedure (random selection) is identical to Jove's. According to Wierenga, then, Thor is equivalent to Jove, and so does not - after all constitute a counterexample to the Howard-Snyders' claim that Jove is unsurpassable.

But: I question Wierenga's claim that (on these assumptions) Thor's and Jove's partition principles are equivalent. Wierenga's stated reason for thinking so is that both partition principles on this view leave infinitely many acceptable worlds both above and below the point of partition. But this reasoning is unpersuasive: analogous reasoning would 'establish' that the numbers 1 and 800 are equivalent, since both are smaller than infinitely-many numbers, and larger than infinitely-many other numbers. ${ }^{48}$ Thor's partition principle may not exclude numerically more acceptable worlds than Jove's does, but it nevertheless expresses a genuinely higher standard.49 Accordingly, Wierenga has failed to show that Thor does not outstrip Jove.

There might, however, be another way to understand Wierenga's no-minimally-acceptableworld claim. Consider, for example,

\section{NMAW2: The predicate 'acceptable' is vague: there is no precise minimal axiological status sufficient for rendering a world 'acceptable' (just as there is no precise minimum number of grains of sand sufficient for comprising a heap).}

But this proposal is also fraught with difficulties. For one thing, it cannot establish the desired equivalency between Thor and Jove: if 'acceptable' is a vague term, it does not follow that Thor and Jove reject an equal number of worlds as unacceptable. And even if they do both still reject infinitely-many worlds on this account, it does not follow tout court that their status as rational and moral agents is equivalent. More importantly, however, it is far from clear that NMAW2 is a coherent proposal. There are many theories of vagueness, but it is reasonable to say that vagueness is either a real feature of the world ('ontic vagueness') or else it is a type of ignorance ('epistemic vagueness') or else it is a feature of language or classical logic. But as noted in Section 2, the term 'acceptable' in this context cannot (on pain of begging the question) mean that a world, on NPW, is capable of actualization by God. 'Acceptable', I argued, must be understood in a weaker, epistemic sense: a world is 'acceptable' when God is not obviously (to us) precluded from actualizing it. Accordingly, the relevant sort of vagueness must be epistemic. But, of course, the failures of knowledge that give rise to epistemic vaguess (on 'epistemicism') are failures of human knowledge, and these are irrelevant to the divine case. Even if - from our point of view - there is no clear answer to whether a given world is acceptable, this is not a problem for an omniscient. So NMAW2 cannot rehabilitate Wierenga's argument. I conclude that Wierenga's attempt to defend the unsurpassability of Jove fails.

\section{CONCLUSION}

The a priori argument for atheism is a formidable challenge to the consistency of traditional theism and the hypothesis of no prime worlds. If this argument is sound, the theist must either give up (or modify) her traditional theistic belief, or reject NPW. Daniel and Frances Howard-Snyders' intriguing effort to undermine this argument depends on the coherence of their proposal that Jove, an essentially-unsurpassable being, could - consistently with his goodness and rationality randomly select a world for actualization. I have argued that William Rowe's new attempt to criticize the Howard-Snyders fails as stated, but I endorsed the spirit of one of his moves: I suggested that the Howard-Snyders have shown neither that (a) Jove's partition principle should be deemed unsurpassable; nor that (b) Jove's decision procedure is unsurpassable. Edward 
Wierenga's new attempt to vindicate the Howard-Snyders' thought-experiment depends on his innovative suggestion that there may not be a least member of the set of acceptable worlds. I have distinguished several ways in which this suggestion might be interpreted, and I have suggested that none can successfully support the claim that Jove is unsurpassable. It seems, then, that the theist cannot rely on the Howard-Snyders' thought-experiment to block the a priori argument for atheism on NPW. 


\section{NOTES}

I thank Nathan Ballantyne, Andrew Hunter, Jim Dianda, Bob Murray, Glenn Parsons, and Josh Mozersky for helpful comments on earlier drafts. I gratefully acknowledge the generous research support I received from Ryerson University's New Faculty Development Fund in Fall 2004.

\footnotetext{
${ }^{1}$ The expression 'prime world' is due to Bruce Langtry (in "God and the Best", Faith and Philosophy 13 (1996): 311-328). NPW differs from NBW (the view that there is no best world) only if there are possible worlds that God does not have the power to actualize. For an argument to this effect, see Alvin Plantinga, The Nature of Necessity, Oxford: Clarendon Press, 1974, 169-184. In what follows, I will assume (for simplicity only, and leaving considerations of goodness and rationality aside) that there are no possible worlds that God does not have the power to actualize. Space does not permit a detailed excursion into difficult questions concerning what sorts of factors contribute to (or detract from) the goodness of worlds, how these factors so contribute (or detract), whether all worlds are commensurable, etc. Accordingly, I will also assume (again, merely for simplicity) that worlds can be ranked in terms of goodness, that there are no ties, and that all worlds are commensurable.
}

${ }^{2}$ William Rowe defends an argument of this sort in an influential series of publications ("The Problem of Divine Perfection and Freedom", in Reasoned Faith [E. Stump, Ed.], Ithaca: Cornell University Press, 1993, 223-233; "The Problem of No Best World", Faith and Philosophy 11 (1994): 269-271; "Evil and God's Freedom in Creation", American Philosophical Quarterly 36: 1999, 101-113; "Can God Be Free?", Faith and Philosophy 19: 2002, 405-424; and Can God Be Free?, Oxford: Oxford University Press, 2004). Arguments in this vein are also advanced by Philip Quinn ("God, Moral Perfection, and Possible Worlds", in God: The Contemporary Discussion, [F. Sontag and M.D. Bryant, Eds.], New York: The Rose of Sharon Press, Inc. (1982): 197-213); Richard Gale, (On The Existence and Nature of God, Cambridge: Cambridge University Press (1991): 30-31); Stephen Grover ("Why only the Best is Good Enough", Analysis 48 (1988): 224, "This World, 'Adams Worlds', and the Best of All Possible Worlds", Religious Studies 39 (2003): 145-163; and "Rival Creator Arguments and the Best of all Possible Worlds", Sophia 43 (2004): 101-114); Jordan Howard Sobel, (Logic and Theism: Arguments for and Against Beliefs in God, Cambridge: Cambridge University Press (2004): 468ff); and Eric Wielenberg, (“A Morally Unsurpassable God Must Create the Best”, Religious Studies 40 (2004): 43-62).

3 While obviously connected to the problem of evil, this is not an argument from evil, since such arguments are a posteriori.

4 This formulation of the argument is mine. In "William L. Rowe's A Priori Argument for Atheism" (Faith and Philosophy 22: 2005), I replied to Thomas Morris' criticism of P1 (from "Perfection and Creation", in Reasoned Faith E. Stump, Ed.], Ithaca: Cornell University Press, 1993, 234-247) and Bruce Langtry's criticism of P2 (from "God and the Best"). But I also urged that a robust defence of P1 and P2 is needed in order for this argument to be persuasive.

5 This is a straightforward consequence of NPW.

${ }^{6}$ Three clarifications are needed here:

(1) This premise may sound consequentialist, but it is not wedded to any particular account of the relationship between the goodness of outcomes and the goodness of actions. For more in this vein, see Earl Conee, "The Nature and Impossibility of Moral Perfection", Philosophy and Phenomenological Research 54 (1994): 821.

(2) If the goodness of the world-actualizing action is itself a contributing factor to the overall goodness of the resulting world, then, given the ceteris paribus clause, P1 is trivially true. (The state of affairs consisting in a world-actualizing action, after all, is included in the state of affairs that comprises that world.) Since P1 is intended to be a substantive claim, I propose to treat the goodness of a world independently of the goodness-conferring role that might be played by the relevant actualizing activity. 
(3) The consequent of this conditional claims that it is possible for an action to have been 'better', and the consequent of P2 claims that it is possible for a being to have been 'better'. Some authors, like Rowe, understand these claims to concern moral surpassability, but they may equally be understood to concern rational surpassability (as, for example, Jordan Howard Sobel does). Everything I say below is consistent with either interpretation of $\mathrm{P} 1$ and $\mathrm{P} 2$.

7 The second horn of this dilemma will be unpalatable to many theists for the following reason: if there is a prime world, it is widely held (on Leibnizian grounds) that God must actualize it. But then the theist must claim that the actual world - appearances quite to the contrary - is unsurpassably good.

8 "How an Unsurpassable Being Can Create a Surpassable World", Faith and Philosophy 11 (1994): 260-267. Their stated targets are Quinn ("God, Moral Perfection, and Possible Worlds") and Rowe ("The Problem of Divine Perfection and Freedom”).

9 Jove is essentially omnipotent and omniscient. Rowe claims that the Howard-Snyders do not assume Jove to be morally unsurpassable, "in order not to beg the question at issue" ("The Problem of No Best World", 269, note 2.) It is true that in their initial presentation of the thought-experiment, Jove is not stipulated to be morally unsurpassable ("How an Unsurpassable Being can Create a Surpassable World", 260). But this is a mere heuristic device: the Howard-Snyders next explicitly add the claim that Jove is essentially morally unsurpassable. Their strategy is to posit this description of Jove, in order then to determine whether a contradiction can be found between this account and NPW. (And see note 6, point 3.)

10 The Howard-Snyders appear to assume that every possible world is actualizable: "Out of his goodness, Jove decides to create. Since he is all-powerful, there is nothing but the bounds of possibility to prevent him from getting what he wants" ("How an Unsurpassable Being can Create a Surpassable World", 260). But see note 1.

${ }^{11}$ The Howard-Snyders say little about what the sorting criteria might be - they merely offer candidates: "For example, he puts on his left worlds in which some inhabitants live lives that aren't worth living and on his right worlds in which every inhabitant's life is worth living; he puts on his left worlds in which some horror fail to serve an outweighing good and on his right worlds in which no horror fails to serve an outweighing good. (We encourage the reader to use her own criteria)" (ibid).

${ }^{12}$ It is not clear to me whether an omniscient agent would know in advance what number the randomizer would generate. In either case, however, Jove's knowledge (or lack thereof) seems irrelevant to the HowardSnyders' argument. But for complaints on this point, see Grover ("This World, 'Adams Worlds', and the Best of All Possible Worlds", 148-151).

13 "How an Unsurpassable Being can Create a Surpassable World", 261. The Howard-Snyders refer to moral unsurpassability in this quotation, but I omit the modifier for reasons given in note 6, point 3. Several authors, including the Howard-Snyders in this passage, refer to the 'creating' of possible worlds. Strictly speaking, possible worlds are states of affairs which can neither be created nor destroyed, and so 'actualizing' is a better term. In what follows, then, I will read 'creating' as 'actualizing' when it occurs in the literature.

${ }_{14}$ It is not clear from the text whether the Howard-Snyders mean to undermine P1 or P2. In personal correspondence, Daniel Howard-Snyder assures me that their intended target was P2: "We definitely took ourselves to be undermining P2, if moral goodness is what's under discussion. I suppose we were granting for the sake of argument, but only for the sake of argument - that P1 is true" (June 27, 2001). In "William L. Rowe's A Priori Argument for Atheism", I followed them in this. Interestingly, however (as we will see below), it becomes more natural to treat them as rejecting P1, once they stipulate that Jove acts on the highest partition principle that there is.

15 “The Real Problem of No Best World”, Faith and Philosophy 13 (1996): 424.

${ }^{16}$ Rowe says:

I use the expression 'acceptable world' to pick out a world that a knowledgeable world creator may choose to create given that creator's degree of goodness and given that it is in 
that creator's power to create an even better world instead ... when confronted with an infinity of increasingly better creatable worlds, a creator with a lessor [sic] degree of goodness will see some creatable worlds as acceptable for creation that a creator with a greater degree of goodness will reject as unacceptable (Can God be Free?, 95, note 15. See also "Can God be Free?", 414).

17 Wierenga refers to 'permissible' and 'impermissible' worlds (in "The Freedom of God", Faith and Philosophy 19 (2002): 425-436.) This locution suffers from the same drawback.

18 "How an Unsurpassable Being can Create a Surpassable World”, 264-265.

19 ibid., 264. Rowe objects to this characterization of Thor (in "The Problem of No Best World", 270), and I discuss his objection in "William L. Rowe's A Priori Argument for Atheism".

20 "The Problem of No Best World", 269-270. Rowe's point might, of course, be recast to concern rational surpassability. For a qualification concerning moral surpassability, see Rowe, Can God be Free?, 93, note 12.

${ }_{21}$ "The Real Problem of No Best World", 423.

${ }^{22}$ Given that Thor's partition point differs from Jove's, it might make sense to describe them as having a different ordinal system: the least of the worlds that Thor is prepared to actualize, strictly speaking, should bear the number ' 1 ', even though the very same world has a different status in Jove's ranking. This is needlessly complicated, however, and so I will continue to use J ove's ordinals when referring to Thor's set of acceptable worlds.

23 The Howard-Snyders think that any principle that justifies a bisection must satisfy the following conditions ("The Real Problem of No Best World", 424):

(1) It divides the set of possible worlds into two groups (the acceptable and the unacceptable);

(2) It is a reasonable principle that a morally good being might well use to sort worlds; and

(3) It is such that it is not irrational [or immoral] to act in accordance with it without acting in accordance with one which expresses a higher standard.

24 “...if there is a finite number of principles that meets these constraints, then we can stipulate that Jove acts on the highest of them, and thus Rowe's story about Thor is obviously incoherent, (since it has Thor acting on a higher principle than Jove) and poses no objection to our argument" (ibid., 423). Of course, it does not follow from the fact that a series is finite that one unique member of that series is highest. The strongest conclusion that is warranted is that at least one is unsurpassably high, so I will interpret the Howard-Snyders in this manner.

25 If it is the Howard-Snyders' intention to suggest here that Jove's world-actualizing action is unsurpassable, then (given that they concede that a better product of this action is possible) they are in fact better interpreted to reject premise P1 from the a priori argument for atheism. See note 14, above. (That said, I will urge in Section 4.1. that the Howard-Snyders' stipulation that Jove's selection of a partition principle is unsurpassable - even if plausible - does not entail that Jove's world-actualizing action is unsurpassable, since the former is only one component of the latter.)

${ }^{26}$ I will not discuss this dilemma here.

27 “Can God be Free?”, 414; and Can God be Free?, 95.

28 "How an Unsurpassable Being can Create a Surpassable World", 263-4.

29 "Can God be Free?", 414; and Can God be Free?, 95. In this passage, Rowe labels his world-creating principles 'P1' and 'P2', but, in order to avoid confusion with the crucial premises in the a priori argument for atheism, I have renamed Rowe's principles 'PrA' and 'PrB'. 
3o ibid; and Can God be Free?, 96.

31 ibid; and Can God be Free?, 97.

32 In "William L. Rowe's A Priori Argument for Atheism", I noted that the Howard-Snyders offer only three weak claims in defense of this claim:

(1) "It seems odd to say the least that there should be infinitely many such general principles."

(2) "At least we see no reason to accept that there are [infinitely many such general principles]."

(3) "...it is not reasonable to believe that there are infinitely many principles which satisfy [the noted] constraints." (“The Real Problem of No Best World”, 424-425).

33 I offered examples of plausible world-good-making-properties (WGMPs) which are degreed, and (arguably) incapable of being maximally instantiated. Partition principles based on such properties, I claimed, could be devised ad infinitum, such that - contra the Howard-Snyders - none would be unsurpassable.

34 “The Freedom of God", 2002.

35 As we will see below, this proposal will require relaxing the earlier stipulation that each world's 'acceptability ordinal' is an integer.

36 "The Freedom of God", 432. In his discussion of the problem of evil, Peter van Inwagen offers a related claim: he suggests that there is "... no minimum number of cases of intense suffering that God could allow without forfeiting the good of a world that is not massively irregular" ("The Problem of Evil, the Problem of Air, and the Problem of Silence", reprinted in van Inwagen, God, Knowledge, and Mystery: Essays in Philosophical Theology, [Ithaca: Cornell University Press, 1995], 77, note 11.) He elaborates on this suggestion in "The Magnitude, Duration, and Distribution of Evil: A Theodicy", Philosophical Topics 16 (1988): 161-187 (also reprinted in God, Knowledge, and Mystery) and in "The Argument from Particular Horrendous Evils" Proceedings of the Catholic American Philosophical Association 74 (2000): 65-80.

37 ibid., emphasis added.

${ }^{38}$ It might be tempting to treat Wierenga as denying P1, since on his view, Thor does actualize a better world than Jove does, but it is false that his world-actualizing action is better: he uses the same decision procedure as Jove does, and his partition principle is equivalent to Jove's, since both are held to be baseless and (hence) arbitrary. But this cannot be, since P1 states merely that

If it is possible for the product (or outcome) of a world-actualizing action performed by some being to have been better, then, ceteris paribus, it is possible for that action to have been better.

Even if Wierenga establishes that Thor's action does not in fact outstrip Jove's, it doesn't follow that Thor's action (or somebody else's action) could not possibly outstrip Jove's action. So Wierenga's argument, if successful, establishes at most that Thor fails to surpass Jove: it has no further force against the a priori argument for atheism.

39 Wierenga might be tempted to reply that every world-actualizing being on NPW will have to use a baseless or arbitrary partition principle. But this move might be construed as tantamount to conceding that no unsurpassable being is possible on NPW.

40 For more on this, see "William L. Rowe’s A Priori Argument for Atheism".

${ }^{41}$ On this point, see Rowe, Can God Be Free?, 135-6.

42 On this view, then, it turns out that neither Thor nor Jove partitions the set of all actualizable worlds at the objective threshold of acceptability. More on this below. 
43 Strictly speaking, Rowe does not quite deny NMAW: he says only that "...the infinite series of decreasingly good worlds envisaged by Wierenga is inapplicable to the topic of good experienced by creatures, and, therefore, ineffective as a response to the problem we've posed" (Can God Be Free?, 136). But one might use considerations like Rowe's in an argument against NMAW.

44 ibid., 136. This passage contains two minor infelicities:

(1) Rowe speaks as though Weirenga has in mind 'good' worlds, but it would be more precise to speak of 'acceptable' (or 'permissible') worlds, since that is the set with which Weirenga is concerned. Unacceptable worlds, after all, may well be 'good', even if no acceptable world could fail to be 'good'.

(2) Rowe slides from talking about undetectable difference in goodnesss (in the first sentence) to talking about undetectable differences in the realm of pains and pleasures (in the remaining sentences). Perhaps, though, differences between various pains and pleasures are by definition detectable.

45 This is a defensible interpolation, given that Wierenga is here explicitly concerned with acceptable worlds. (He calls them 'permissible' worlds.)

46 “The Freedom of God”, 432.

47 ibid.

48 Rowe makes a similar point:

Wierenga is claiming, I believe, that it makes sense to think that Thor ... has a higher standard of world creation than Jove only if Thor rejects a larger number of worlds than is rejected by Jove. Apparently it is not enough for Wierenga that Thor's standard for world creation requires him to reject not only all the worlds (an infinite number) that Jove rejects, but also some worlds that Jove finds acceptable, including the world that Jove elects to create. And Thor rejects those worlds, we may suppose, because his own standard of world creation is such that he judges those worlds to be not good enough for him to create, provided he can create a better world. My own best judgment is that Wierenga has failed to show that it makes no sense in the 'no least good world scenario' to suppose that Jove acts on a higher standard of world creation than does Thor. For it remains true that Thor elects to create a better world than the world Jove elects to create, and true also that Thor chooses that world over the world chosen by Jove because it is a better world (Can God Be Free?, 139-140).

49 And, if - as I argued above - the Howard-Snyders are not entitled to stipulate that Jove's partition principle is unsurpassable, then Thor surpasses Jove. 